\title{
Thoracoscopic approach in the treatment of ectopic thymic parathyroid adenoma
}

\author{
Virgilijus Beiša, Neringa Pranskevičiūtè, Gabija Makūnaitè, Kęstutis Strupas \\ Centre of Abdominal Surgery, Clinic of Gastroenterology, Nephrourology and Surgery, Institute of Clinical Medicine, Faculty of Medicine, \\ Vilnius University, Vilnius, Lithuania
}

Videosurgery Miniinv 2018; 13 (2): 270-277

DOI: https://doi.org/10.5114/wiitm.2018.73331

\begin{abstract}
Primary hyperparathyroidism is overproduction of parathyroid hormone, causing hypercalcemia. Parathyroid adenomas have been found to be the etiology for $80 \%$ of cases of primary hyperparathyroidism, while almost a quarter of them are ectopic. We present a case of ectopic thymic parathyroid adenoma, treated by the thoracoscopic approach. Preoperative computed tomogram and technetium-99-sestamibi imaging showed an adenoma, located in the front mid-mediastinum, approximately $8 \times 10 \mathrm{~mm}$ in size. Resection of the tumor was indicated according to the persistent hypercalcemia after unsuccessful surgical treatment performed 3 years ago. It was decided to perform a parathyroidectomy during thoracoscopy. The diagnosis of parathyroid adenoma was established on postoperative histopathology staining. The patient was discharged from hospital 5 days after the surgery. We found this minimally invasive operation to be an effective and well-tolerated treatment option, determined by the experience of the surgeon.
\end{abstract}

Key words: primary hyperparathyroidism, thoracoscopic surgery, parathyroidectomy, ectopic parathyroid.

\section{Introduction}

Primary hyperparathyroidism is overproduction of parathyroid hormone, causing hypercalcemia. It is the third most common endocrine disease and usually affects postmenopausal women [1-4]. Parathyroid adenomas have been found to be the etiology for $80 \%$ of primary hyperparathyroidism cases, while almost a quarter of them are ectopic [5, 6]. Mostly, abnormal parathyroid glands are found in the superior mediastinum within the thymus [4]. Primary hyperparathyroidism usually causes no symptoms and it is diagnosed incidentally because of hypercalcemia, found on routine laboratory evaluation and with elevated levels of parathyroid hormone. The challenge of differentiating hypercalcemia, associated with hyperfunction of the parathyroid gland, from hypercalcemia caused by metastatic cancer, multiple myeloma, sarcoidosis, other granulomatous diseases, ingestion of calcium or vitamin D, is a part of the diagnostic process [7]. Imaging modalities, such as cervical ultrasound, computed tomography and magnetic resonance imaging, are used for the diagnosis and localization of parathyroid adenoma. Therefore, the gold standard for localization, especially to identify mediastinal adenomas, is technetium-99m sestamibi scanning [8, 9]. For a mild disease it is possible to try medical management with bisphosphonates, hormone replacement therapy and calcimimetics. However, more frequently, primary hyperparathyroidism is cured by surgical removal of an adenoma [3]. An ectopic parathyroid adenoma, located in the mediastinum, as described in this case, is traditionally treated by median sternotomy, manubriotomy or open thoracotomy [6, 10-12]. 
Recently, advances in minimally invasive thoracic surgery techniques have decreased the need for a conventional approach to remove these ectopic parathyroid glands [13].

We present a patient with hyperparathyroidism due to ectopic thymic parathyroid adenoma, who underwent total resection via a thoracoscopic approach.

\section{Case report}

A 50-year-old female patient presented to our clinic for resection of an ectopic parathyroid gland.
The patient had no severe complaints before hospitalization. According to the anamnesis, thyroidectomy was performed 15 years ago, because of compression syndrome (neck surface deformation, pressure in the neck, difficult swallowing) and symptoms of hyperthyroidism (palpitation, tachycardia, emotional lability) caused by a toxic multinodular goiter. The surgery was performed successfully, and no signs of laryngeal recurrent nerve lesion or hypocalcemia were observed. Three years ago the patient was hospitalized repeatedly because of hypercalcemia which was diagnosed via laboratory tests

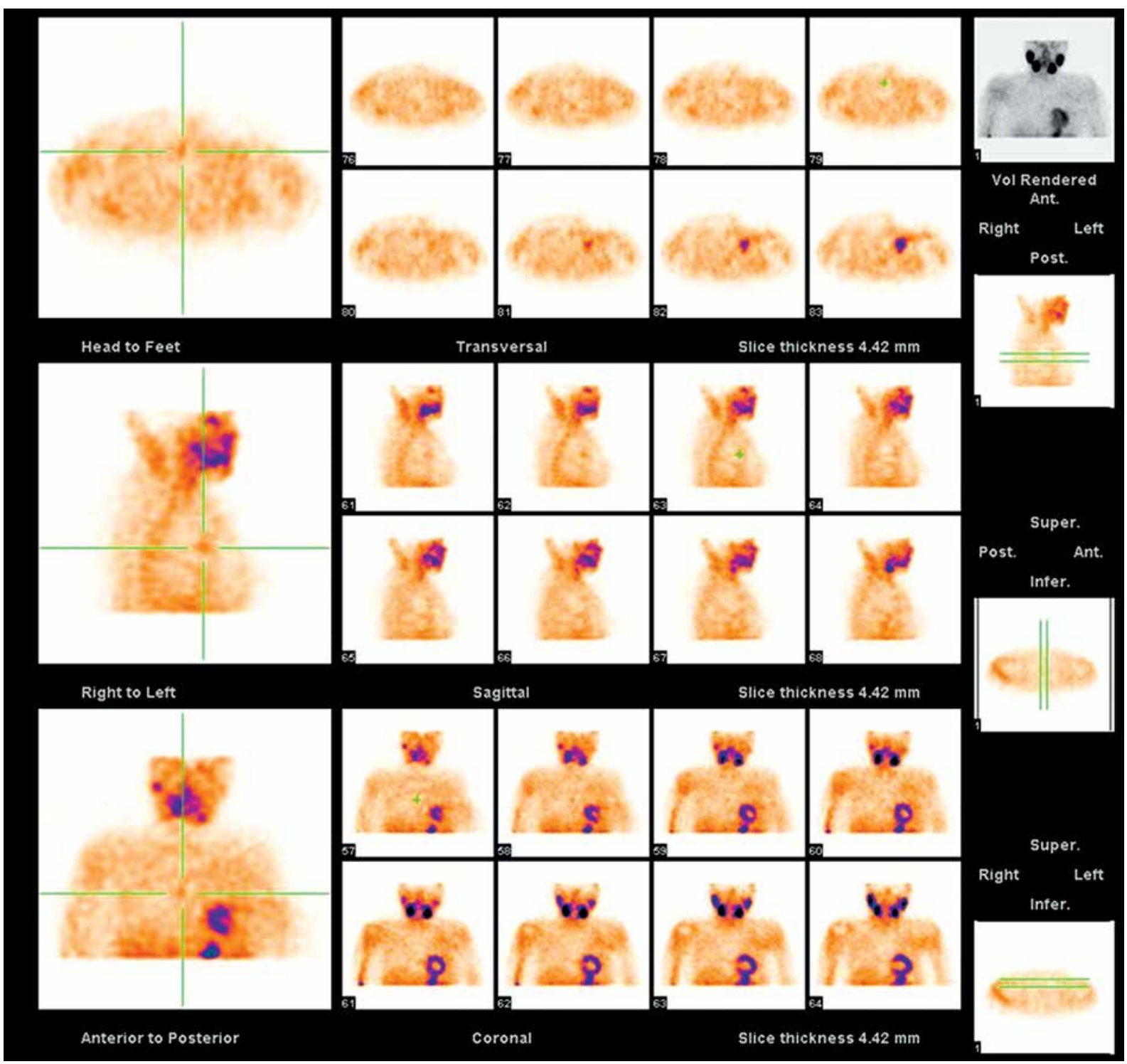

Photo 1. Technetium-99m sestamibi scanning showing focal uptake in the mediastinum 
(ionized calcium concentration in the venous blood was $1.45 \mathrm{mmol} / \mathrm{l}$ and parathyroid hormone (PTH) concentration was $49.63 \mathrm{pmol} / \mathrm{l})$. Simultaneously, osteopenia was diagnosed via performing a DEXA scan. In addition, neck ultrasound and scintigraphy tests were performed; there were insufficient data for parathyroid gland adenoma. It was decided to perform left superior parathyroidectomy and resection of residual thyroid tissue. The left superior parathyroid gland was enlarged twice; it was round and visually similar to adenoma. Other parathyroid glands were revised during the procedure. The left inferior and right superior parathyroid glands were without visible pathological changes. The right inferior parathyroid gland was not found. Resection of the thymus gland on both sides was performed. Ectopic parathyroid glands were not found in the resected thymus tissue. Below the manubrium on the trachea, a thyroid gland of approximately $3 \mathrm{~cm}$ in diameter was found, which was removed. An urgent histological examination was performed during the surgery, which revealed that the removed tissues were a thyroid fragment and a parathyroid gland without pathohistological changes. The PTH concen-

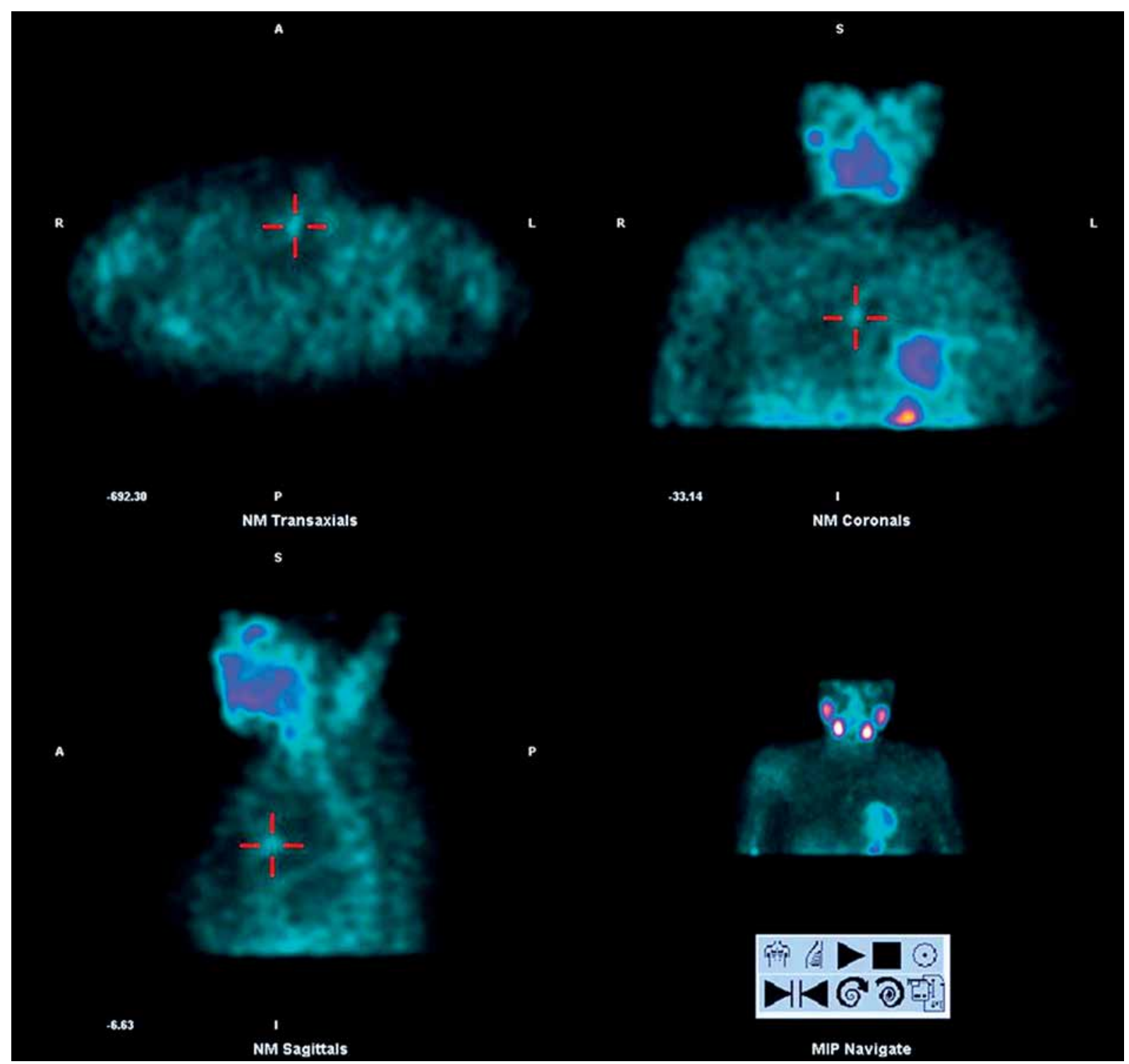

Photo 2. Technetium-99m sestamibi scanning showing focal uptake in the mediastinum 
tration in the blood prior to the removal of the parathyroid gland was $10 \mathrm{pmol} / \mathrm{l}$, and after elimination $54 \mathrm{pmol} / \mathrm{l}$. During the operation, all neck areas were revised, but the adenoma of the parathyroid gland was not found. The PTH concentration during the first postoperative day was $32.9 \mathrm{pmol} / \mathrm{l}$.

Half a year ago the patient underwent chest computed tomography scan and technetium-99m sestamibi scanning (Photos 1-4). Imaging findings: in the front mid-mediastinum there was observed a for- mation, approximately $8 \times 10 \mathrm{~mm}$ in size and with unclear boundaries - a potential ectopic parathyroid gland. The case was discussed in an interdisciplinary patient discussion involving endocrinologists and surgeons. It was decided to perform a parathyroidectomy during thoracoscopy.

On June 5, 2017 the patient presented for a planned operation. The serum PTH concentration at that time was $31.3 \mathrm{pmol} / \mathrm{l}$, the serum Ca concentration was $2.81 \mathrm{mmol} / \mathrm{l}$. Thoracoscopy and remov-
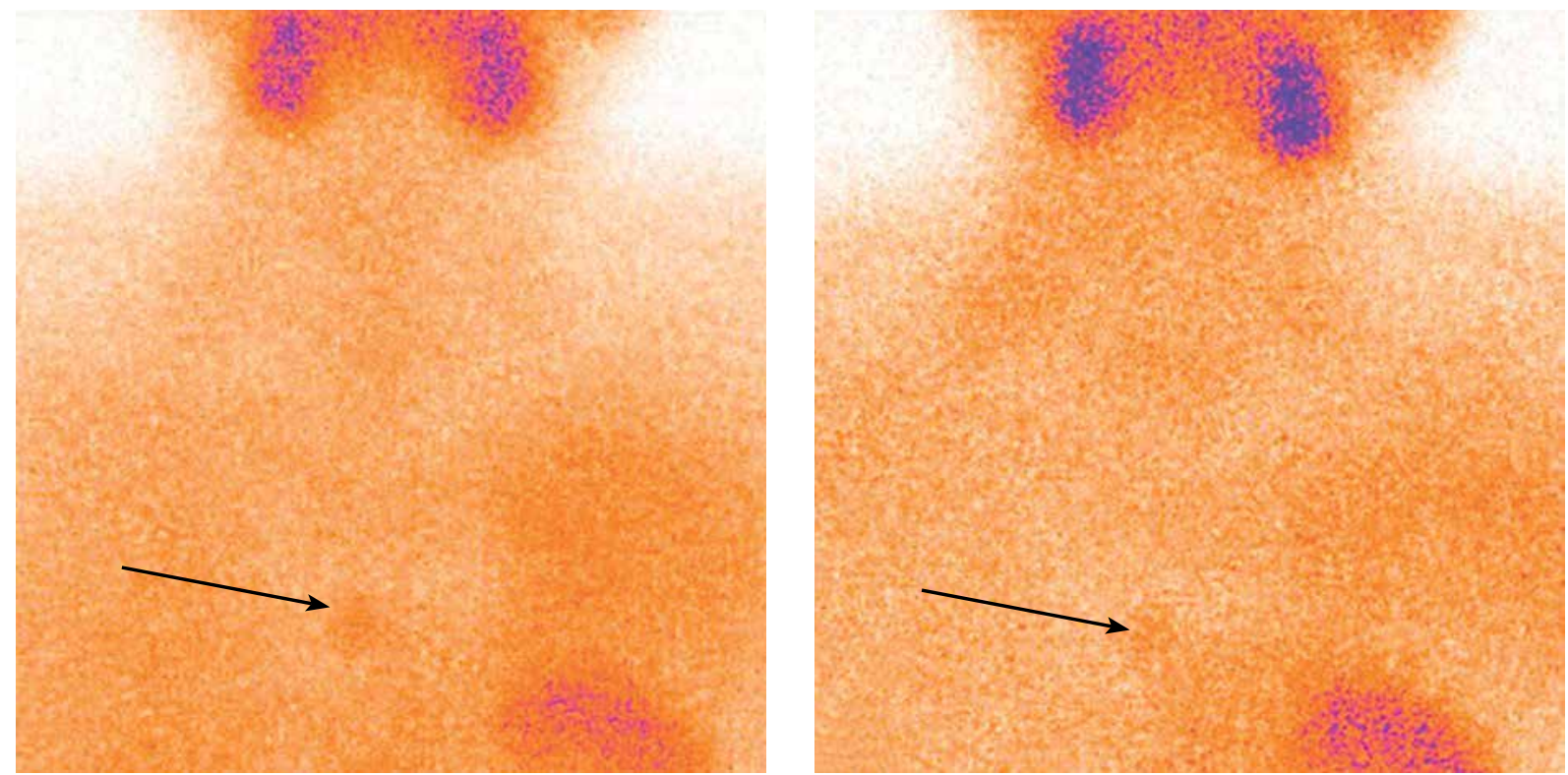

Photo 3. Technetium-99m sestamibi scanning showing focal uptake in the mediastinum
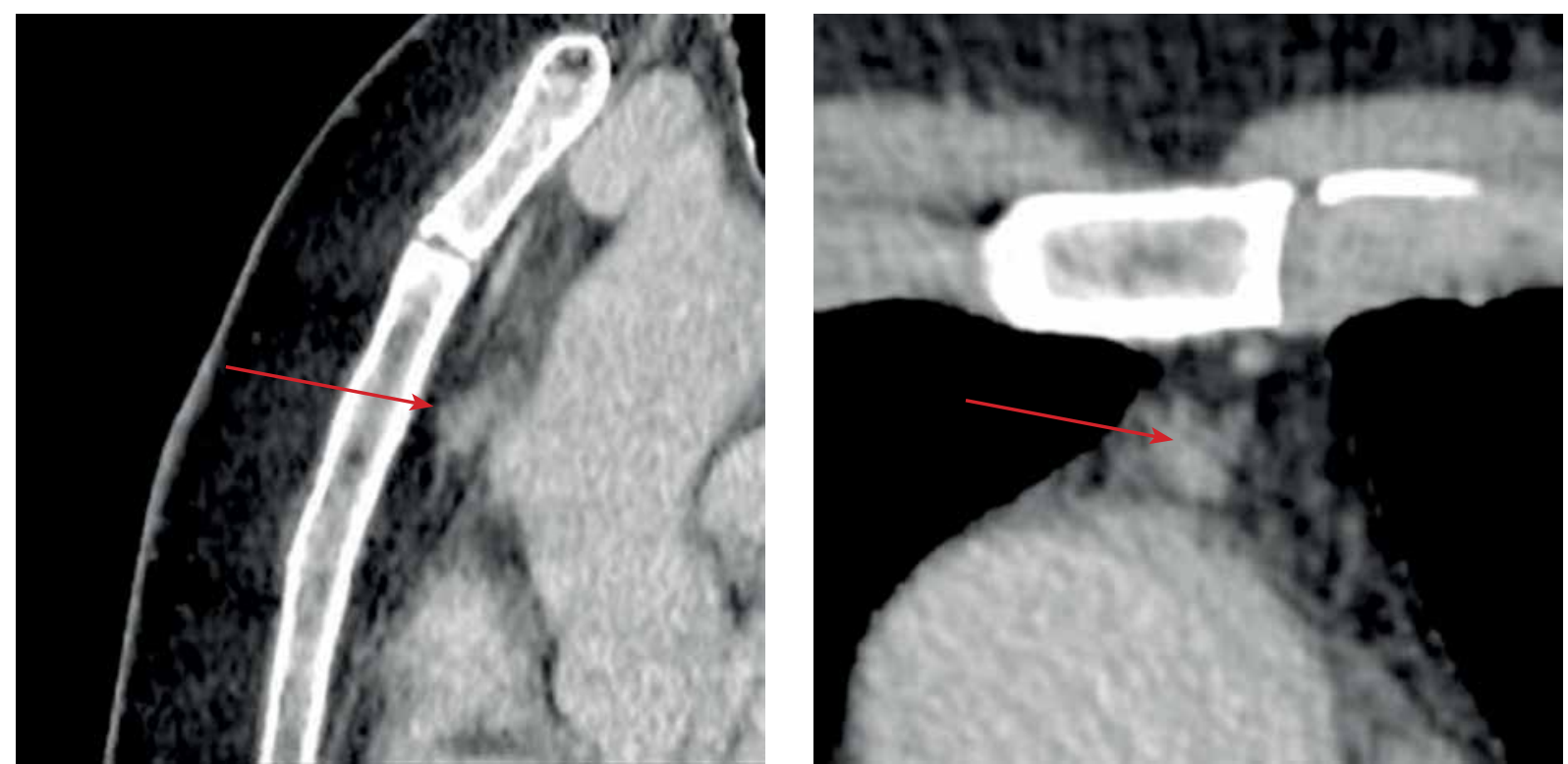

Photo 4. Preoperative computed tomographic (CT) scan 


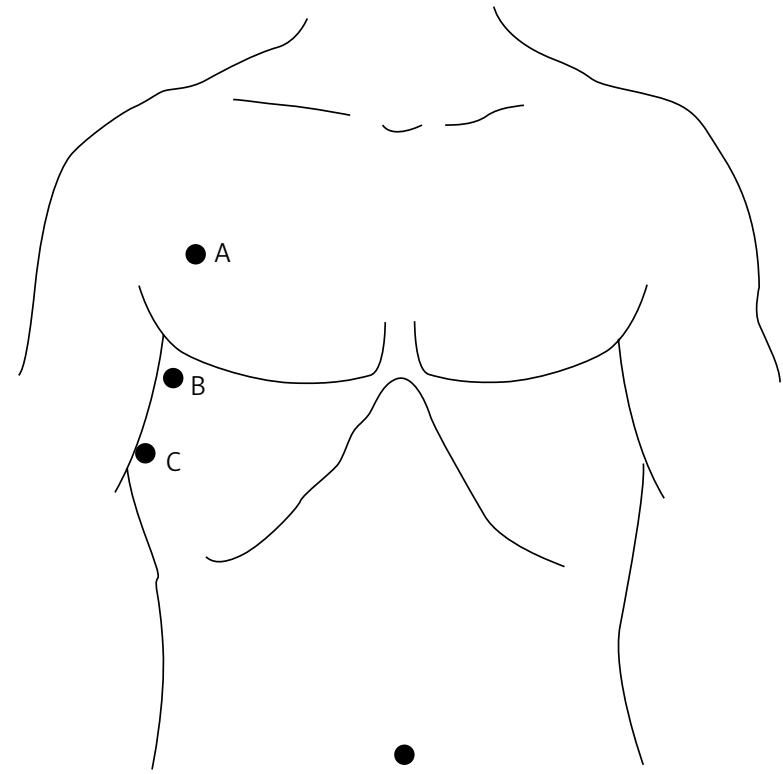

Figure 1. Positioning of trocars: $A-10 \mathrm{~mm}$, B - $10 \mathrm{~mm}, \mathrm{C}-5 \mathrm{~mm}$

al of the adenoma of the right ectopic parathyroid gland were performed. The patient's position was semi-turned on the left side. After preparation of the surgical field, two $10 \mathrm{~mm}$ trocars and one $5 \mathrm{~mm}$ trocar were inserted into the chest through intercostal spaces II, IV and VII (Figure 1). During the examination of the thymus gland, the adenocarcinoma was not visible or palpated. The mediastinal pleura was cut with an ultrasound scalpel in the corner of the vena cava inferior and pericardium. The thymus was separated from the right and left brachiocephalic veins in a cranial direction along the right phrenic

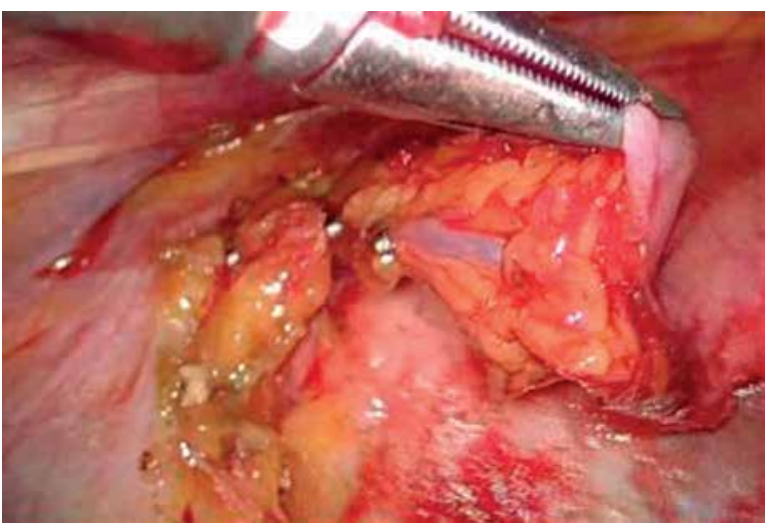

Photo 5. Perioperative videothoracoscopic image. The thymus was separated and thymic veins were pressed with metal clips nerve. The thymic veins were pressed with metal clips (Photos 5, 6). The thymus was separated from the aortic arc and the thymus gland was examined by an endoscopic ultrasound sensor. Nearly at the right edge of the thymus, an approximately $10 \mathrm{~mm}$ hypoechogenic formation was observed: a suspected adenoma of the parathyroid gland. The thymus with adenoma of ectopic parathyroid gland was removed. The size of the removed adenoma was $10 \times$ $10 \times 8 \mathrm{~mm}$, and the weight was $750 \mathrm{mg}$ (Photo 7). The overall operative time was $95 \mathrm{~min}$. Histological examination of the removed tissue was performed: the final diagnosis of the pathology was ectopic parathyroid gland.

The serum PTH concentration during the first postoperative day was $4.3 \mathrm{pmol} / \mathrm{l}$, and the serum Ca concentration was $2.02 \mathrm{mmol} / \mathrm{l}$. The postoperative period was smooth, and no complications were observed in the early period. On the fifth postoperative day, in a satisfactory condition, the patient was discharged from the hospital (Photo 8).

Currently, half a year after the surgery, the patient is asymptomatic, without any evidence of recurrence.

\section{Discussion}

Primary hyperparathyroidism is overproduction of parathyroid hormone, causing hypercalcemia. This is a relatively common disease and can occur at any age, but mostly it affects postmenopausal women [1-3].

Parathyroid hormone (PTH) is a polypeptide which regulates calcium ion concentration in blood

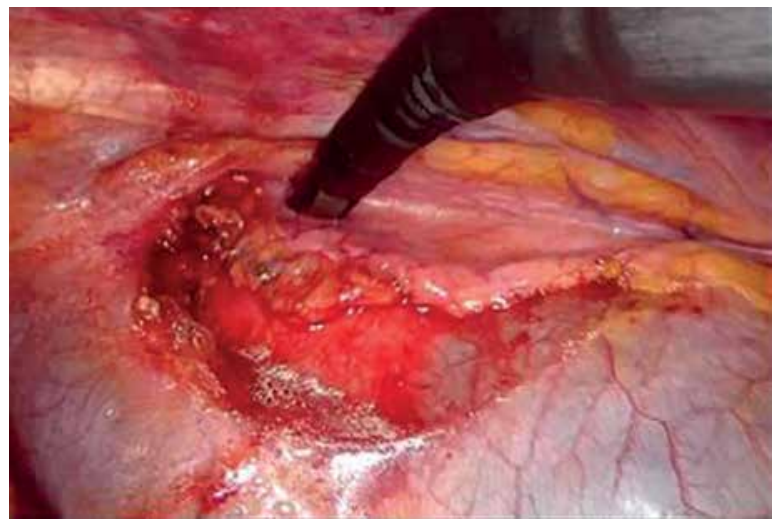

Photo 6. Perioperative videothoracoscopic image. Thymus gland was examined by an endoscopic ultrasound sensor 


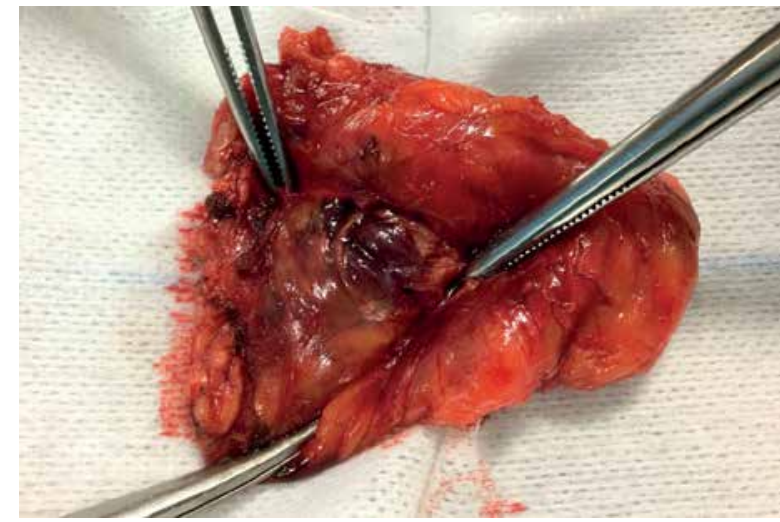

Photo 7. The thymus with adenoma of ectopic parathyroid gland after operation

and extracellular fluid, where it is metabolized, and only $1 \%$ causes an increased calcium level in blood by participating in reactions with bone and kidney cell-surface PTH receptors [14]. Hypercalcemia can be caused by hyperfunction of the parathyroid gland, by metastatic cancer, multiple myeloma, sarcoidosis, other granulomatous diseases, ingestion of calcium or vitamin $D$ and some other rarer diseases [7]. However, PTH hypersecretion and elevated levels of this hormone in the serum allow us to differentiate primary hyperparathyroidism from other causes of hypercalcemia.

Parathyroid adenomas have been found to be the etiology for $80-85 \%$ of primary hyperparathyroidism cases, while only $2 \%$ are carcinomas and parathyroid hyperplasia $[5,6,14,15]$. Almost a quarter of parathyroid adenomas are ectopic, and the most likely to be in an abnormal anatomical localization is the inferior parathyroid gland, mainly being located in the superior mediastinum within the thymus. Other possible positions are the deep anterior mediastinum, the aortopulmonary window, the posterior mediastinum, or within the substance of the thyroid gland $[4-6,16-18]$. The inferior parathyroid glands are extremely variable because of being derived from the third branchial pouch along with the thymus. When it descends into the chest in the $5^{\text {th }}$ week of embryonic development, it is accompanied by the lower parathyroid glands. Occasionally, they move to the chest, along with the thymus $[12,19,20]$. The incidence of normal inferior parathyroid glands located within the thymus varies from $12 \%$ to $39 \%$ [18, 21, 22].

Most patients with hyperparathyroidism are asymptomatic and primary hyperparathyroidism is di-

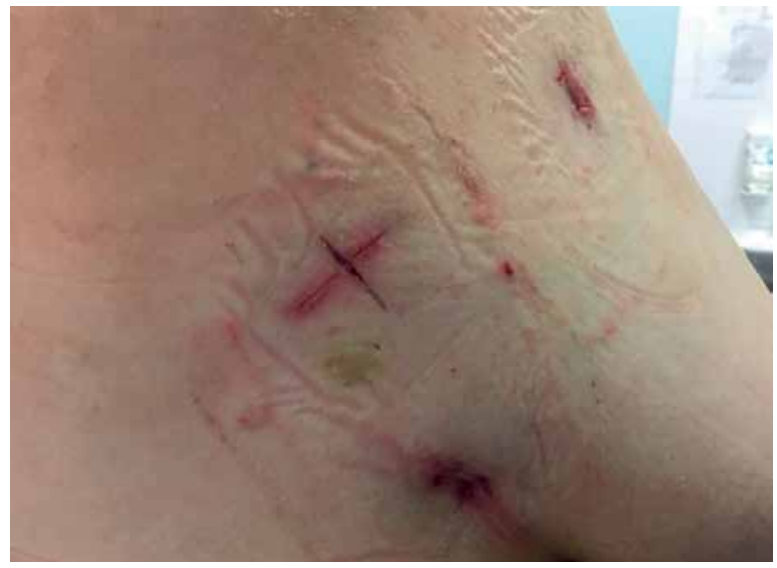

Photo 8. Patient on the fifth postoperative day

agnosed incidentally because of hypercalcemia - the serum calcium level more than $2.6 \mathrm{mmol} / \mathrm{l}$, elevated levels of parathyroid hormone, creatinine clearance reduced to $<60 \mathrm{ml} / \mathrm{min}$ and bone mineral density less than $1.0[1,7,8]$. Hypercalcemia can sometimes cause nausea, vomiting, excessive thirst, constipation, polyuria, lethargy, and cardiac anomalies. Kidney stones, osteoporosis and pathologic fractures may also occur. The level of hypercalcemia correlates with the severity of symptoms [19].

The first successful parathyroidectomy was described in Journal of the American Medical Association in 1929. Over the next 40 years the incidence of primary hyperparathyroidism remained largely unchanged, because it was diagnosed with symptoms of nephrolithiasis, osteitis fibrosa cystica, peptic ulcer disease, psychosis or pancreatitis. In the 1960s the automated chemistry analyzer began to be used, so the disease could be diagnosed much earlier in its course. Nowadays, imaging modalities such as cervical ultrasound, computed tomography and magnetic resonance imaging are used for the diagnosis and localization of parathyroid adenoma. Sometimes it is necessary to perform a reoperation when neck exploration alone is not enough for accurate diagnosis because of an ectopic parathyroid gland [8]. The gold standard for localization of ectopic parathyroid adenoma is technetium-99m sestamibi scanning [8, 9, 23]. More recently, simultaneous positron emission tomography and magnetic resonance imaging is a new hybrid method of imaging that provides excellent soft-tissue contrast and high imaging quality of ectopic mediastinal parathyroid adenomas [24]. However, preoperative localization can be very challenging and sometimes only combinations of tech- 
netium-99m sestamibi scanning, neck ultrasound, computed tomography and magnetic resonance imaging increase the yield in localizing ectopic parathyroid adenoma [12, 25]. Successful preoperative localization of ectopic glands is more likely when the fine needle-aspiration cytology of a suspicious lesion is performed and parathyroid hormone is measured in the aspirated material [18]. Parathyroid adenomas and parathyroid carcinomas can be difficult to differentiate on the basis of preoperative clinical characteristics [26]. The histopathological criteria for parathyroid carcinomas as defined by Schantz and Castleman include thick fibrous bands, mitotic activity, trabecular growth pattern and capsular, vascular and adjacent soft-tissue invasion [15].

Parathyroidectomy has a success rate of more than $95 \%$ for cure of primary hyperparathyroidism [23]. Indications for surgical resection are symptomatic parathyroid adenoma, asymptomatic patients with complications from hypercalcemia or patients who are unable to participate in appropriate follow-ups [8, 11]. In this case surgery was indicated due to the manifestation of persistent hypercalcemia and the osteopenia detected performing the DEXA scan. Both minimally invasive parathyroidectomy and bilateral neck exploration are appropriate operations that achieve high cure rates, depending on the experience of the surgeon $[11,27]$. Over the last half century, the surgical approach to parathyroidectomy has evolved to targeted parathyroidectomy that is directed by preoperative imaging studies and guided by intraoperative parathormone monitoring [10,12], especially for patients in whom the localization studies have identified single gland adenoma or unilateral disease [7]. However, ectopic parathyroid adenomas are the most frequent reason for a failed cervical exploration [28]. Median sternotomy and lateral thoracotomy are the traditional methods for cases of adenoma of the upper mediastinum, and cervicotomy is also a popular option [6, 28]. These surgical approaches are associated with higher risk of injury of the phrenic or recurrent laryngeal nerve, laceration of the brachiocephalic vein, delayed wound healing, wound infection, mediastinitis and even death [29]. Recently, some centers have been implementing minimally invasive surgery for the treatment of ectopic parathyroid adenomas, focused on reducing the size of the incision and minimizing surgical dissection $[13,19,28]$. The reported advantages of thoracoscopic surgery include better visualization of the adenoma, a shorter operative time, reduced soft tissue dissection, shorter tube dwell time and shorter hospital stay, with a superior cosmetic result compared to sternotomy and thoracotomy scars $[13,30]$. In the present case, we used a thoracoscopic approach, because the lesion was located in an appropriate place on the computed tomography scan for a thoracoscopic procedure.

Postoperative observation includes hematoma, evaluation for hypocalcemia or symptoms of hypocalcemia and patients should be followed up to reach normocalcemia at more than 6 months. Calcium supplementation may be indicated postoperatively [11].

To sum up, we found that the thoracoscopic approach for resection of ectopic mediastinal parathyroid adenoma is a safe and successful approach and should be considered as the procedure of choice. Despite the fact that the minimally invasive treatment of ectopic parathyroid adenomas is a challenge for the surgeon, it should be considered because of the obvious advantages, such as shorter operative and hospital stay time, reduced recovery time and better cosmetic result.

\section{Conclusions}

An ectopic parathyroid adenoma, located in the front mid-mediastinum, can be successfully resected through the thoracoscopic approach. We have found this minimally invasive operation to be an effective and well-tolerated treatment option, determined by the experience of the surgeon.

\section{Conflict of interest}

The authors declare no conflict of interest.

\section{References}

1. Nilsson IL, Norenstedt S, Zedenius J, et al. Primary hyperparathyroidism, hypercalciuria, and bone recovery after parathyroidectomy. Surgery 2017; 162: 429-36.

2. Michael WY, Philip HGI, Hui CZ, et al. Incidence and prevalence of primary hyperparathyroidism in a racially mixed population. J Clin Endocrinol Metab 2013; 98: 1122-9.

3. Fraser WD. Hyperparathyroidism. Lancet 2009; 374: 145-58.

4. Daliakopoulos SI, Chatzoulis G, Lamprid S, et al. Gamma probeassisted excision of an ectopic parathyroid adenoma located within the thymus: case report and review of the literature. J Thorac Cardiovasc Surg 2014; 9: 62-70.

5. Noussios G, Anagnostis P, Natsis K. Ectopic parathyroid glands and their anatomical, clinical and surgical implications. Exp Clin Endocrinol Diabetes 2012; 120: 604-10. 
6. Young SK, Jhingook K, Sumin S. Thoracoscopic removal of ectopic mediastinal parathyroid adenoma. Korean J Thorac Cardiovasc Surg 2014; 47: 317-9.

7. Mohebati A, Shaha AR. Imaging techniques in parathyroid surgery for primary hyperparathyroidism. Am J Otolaryngol 2012; 33: 457-68.

8. Kim YS, Kim J, Shin S. Thoracoscopic removal of ectopic mediastinal parathyroid adenoma. Korean J Thorac Cardiovasc Surg 2014; 47: 317-9.

9. Ahuja AT, Wong KT, Ching AS, et al. Imaging for primary hyperparathyroidism: what beginners should know. Clin Radiol 2004; 59: 967-76.

10. Rajaei MH, Oltmann SC, Adkisson CD, el at. Is intraoperative parathyroid hormone monitoring necessary with ipsilateral parathyroid gland visualization during anticipated unilateral exploration for primary hyperparathyroidism: a two-institution analysis of more than 2,000 patients. Surgery 2014; 156: 760-6.

11. Campbell MJ. The definitive management of primary hyperparathyroidism. Who needs an operation? JAMA 2017; 317 1167-8.

12. LoPinto M, Rubio GA, Khan ZF, et al. Location of abnormal parathyroid glands: lessons from 810 parathyroidectomies. J Surg Res 2017; 207: 22-6.

13. Alesina PF, Moka D, Mahlstedt J, et al. Thoracoscopic removal of mediastinal hyperfunctioning parathyroid glands: personal experience and review of the literature. World I Surg 2008; 32: 224-31.

14. Mariani G, Gulec SA, Rubelo D, et al. Preoperative localization and radioguided parathyroid surgery. I Nucl Med 2003; 44: 1443-58.

15. Schantz Z, Castleman B. Parathyroid carcinoma: a study of 70 cases. Cancer 1973; 31: 600-5.

16. Hinson AM, Stack BC Jr. Applied embryology, molecular genetics, and surgical anatomy of the parathyroid glands. In: Medical and Surgical Treatment of Parathyroid Diseases. An Evidence-Based Approach. Stack BC Jr, Brendan C, Bodenner D (eds). USA 2017; 17-25.

17. Yutaka Y, Omasa M, Shikuma K, et al. Video-assisted mediastinoscopic resection of ectopic parathyroid adenoma. Asian Cardiovasc Thorac Ann 2012; 20: 731-3.

18. Noussios G, Anagnostis P, Natsis K. Ectopic parathyroid glands and their anatomical, clinical and surgical implications. Exp Clin Endocrinol Diabetes 2012; 120: 604-10.

19. Oueriachi FE, Arsalane A, Kabiri EH. Uncommon ectopic parathyroid adenoma. Arch Bronconeumol 2015; 51: 301-2.

20. Ruanpeng D, Harindhanavudhi T. Intrathymic parathyroid adenoma. Am J Med Sci 2017; 353: 506-7.

21. Stalberg P, Grodski S, Sidhu S, et al. Cervical thymectomy for intrathymic parathyroid adenomas during minimally invasive parathyroidectomy. Surgery 2007; 141: 626-9.

22. Sellitri F, Tamburrini A, Tacconi F, et al. Intrathymic ectopic parathyroid adenoma caused primary hyperparathyroidism with vitamin D deficiency several years after bariatric surgery. Thorac Cancer 2015; 6: 101-4.

23. Roy M, Mazeh $\mathrm{H}$, Chen $\mathrm{H}$, et al. Incidence and localization of ectopic parathyroid adenomas in previously unexplored patients. World J Surg 2013; 37: 102-6.
24. Purz S, Kluge R, Barthel H, et al. Visualization of ectopic parathyroid adenomas. N Engl I Med 2013; 369: 2067-9.

25. Thanseer N, Bhadada SK, Sood A, et al. Comparative effectiveness of ultrasonography, $99 \mathrm{mTc}$-Sestamibi, and 18F-fluorocholine PET/CT in detecting parathyroid adenomas in patients with primary hyperparathyroidism. Clin Nucl Med 2017; 42: e491-7.

26. Sato S, Kitahara A, Koike T, et al. Resection of a large ectopic parathyroid adenoma: a case report. Int I Surg 2016; 23: 8-11.

27. Barczyński M, Papier A, Kenig J, et al. A retrospective case-controlled study of video-assisted versus open minimally invasive parathyroidectomy. Videosurgery Miniinv 2014; 9: 537-47.

28. Downey NJ, McGuigan JA, Dolan SJ, et al. Median sternotomy for parathyroid adenoma. Ir J Med Sci 1999; 168: 13-6.

29. Hu J, Ngiam KY, Parameswaran R. Mediastinal parathyroid adenomas and their surgical implications. Ann R Coll Surg Engl 2015; 97: 259-61.

30. Amer K, Khan AZ, Rew D, et al. Video assisted thoracoscopic excision of mediastinal ectopic parathyroid adenomas: a UK regional experience. Ann Cardiothorac Surg 2015; 4: 527-34.

Received: 30.11.2017, accepted: 7.01.2018. 